phate is evident. Nevertheless, the polyphosphoric acid seems to be an important factor since, for example, the lethal dose of muscle adenylic acid is much higher than that of adenosine triphosphate.

The replacement of sodium by magnesium in inosine triphosphate much more than compensates for the loss in activity produced by the substitution of the $\mathrm{NH}_{2}$ group in the adenosine triphosphate by the $\mathrm{OH}$ group (inosine triphosphate). This is shown by comparison of the results obtained with magnesium inosine triphosphate and the sodium salts of adenosine triphosphate and inosine triphosphate (Table 1).

It may be assumed, therefore, that the $\mathrm{P}_{2} \mathrm{O}_{7}$ group becomes biologically more active, at any rate so far as its shock-producing effects are concerned, when it is combined with both magnesium and either adenylic or inosinic acids. As we have been unable so far to prepare an inorganic magnesium polyphosphate suitable for injection, we do not yet know whether this is due to the influence of the magnesium ion on the polyphosphoric acid group.

The magnesium salt of adenosine triphosphate had the greatest potency of all the substances tested, and using minimal lethal doses a shock-like condition followed the injection much more rapidly (Table 2). It is noteworthy that the quotient $\mathrm{P}_{2} \mathrm{O}_{7} / \mathrm{P}_{2} \mathrm{O}_{7}$ - magnesium adenosine triphosphate is the same in both species for magnesium adenosine triphosphate, magnesium inosine triphosphate and the striated muscle product (Table 1), whereas there is a considerable difference between the rat and mouse in the quotients for both sodium adenosine triphosphate and sodium inosine triphosphate. A calculation on the basis that all the adenosine triphosphate in the striated muscle product is present as the magnesium salt accounts fully for its vaso-depressor activity (see Table 1). Its lower shock-producing potency after intraperitoneal injection is probably due to a slower rate of absorption of the magnesium adenosine triphosphate from the crude muscle product. All the data at our disposal make it highly probable that the adenosine triphos. phate in striated muscle is present in the form of the magnesium salt. This conception is in good agreement with the results obtained by Szent-Györgyi and his collaborators ${ }^{3}$.

\section{Marian Brelschowsky.}

Department of Pathology,

H. N. GreEn.

University of Sheffield. March 21.

${ }^{1}$ Green, H. N., Lancet, ii, 147 (1943).

'Bielschowsky, M., and Green, H. N., Lancet, ii, 153 (1943).

- Szent-Györgyi, A., Ber., 75, 1868 (1943).

\section{Reaction between Proteins and Formaldehyde}

Ir has been found possible to deamide animal and plant caseins by treatment with a solution of 1 per cent caustic soda for $40 \mathrm{hr}$. at $45^{\circ} \mathrm{C}$. The desamido casein, when hardened with formaldehyde under neutral conditions, combines with the same amount of formaldehyde as does the untreated casein. In the presence of salts, acids (for example, saturated calcium chloride solution and hydrochloric acid) and formaldehyde, the neutral hardened deamided material combines with no additional formaldehyde, whereas the untreated neutral hardened casein may increase its formaldehyde content by about 100 per cent.
Partial deamination is also possible without the removal of amide nitrogen. The partially deaminated product combines with a reduced quantity of formaldehyde under neutral conditions. In contrast to this, the same partially deaminated product combines with a normal quantity of additional formaldehyde when treated with formaldehyde, salt and acid.

Further confirmation of the conception of a reaction between formaldehyde and the amide groups of proteins is given by experiments with the protein zein. Only 0.4 per cent of formaldehyde combines with this protein when it is hardened in a neutral solution. In the presence of salt and acid, however, its combined formaldehyde increases to $4 \cdot 1$ per cent. These figures are in keeping with the low amino and high amide contents of zein.

It is concluded, therefore, that at or near the isoelectric point of the protein, formaldehyde combines with the amino groups mainly derived from lysine residues. Under more acid conditions it combines with the amide groups which are attached to residues of glutamic and related acids. A more detailed account of the investigation will appear elsewhere.

We thank the directors of Messrs. Courtaulds, Ltd. for permission to publish this communication.

R. L. WORMELL.

Courtaulds, Ltd., MaUrice A. G. Kaye.

Foleshill Road,

Coventry.

March 24.

\section{Methionine in the Treatment of Liver Damage}

RECENT investigations on protein metabolism and nutrition have increasingly emphasized the importance of individual amino-acid deficiencies in producing specific clinical states and pathological appearances ${ }^{1}$. It has been shown ${ }^{2}$ that fatty livers can be produced in rats by dietary control. This latter work, and the findings of Miller and Whipple ${ }^{3}$ that methionine could protect the liver against damage by chloroform, suggested to us that the present epidemic of infective hepatitis and the increased incidence of 'postarsphenamine' jaundice might in some measure be conditioned by a sub-optimal protein intake leading to a latent methionine deficiency.

In 1942 we commenced a series of investigations along three main lines: $(a)$ the prevention of liver damage during arsenical treatment for syphilis; (b) the treatment of established liver damage in cases of infective hepatitis and 'post-arsphenamine' jaundice ; and $(c)$ the treatment of patients gravely ill with liver dysfunction extending over a period of many weeks or months. Our observations in the prevention of liver damage during arsenical treatment, to be published in detail shortly, have made it abundantly clear that liver damage can either be prevented or minimized by the administration of methionine or by the use of casein digests rich in methionine which have had cystine added to them. The addition of cystine apparently was of value because of the methionine-sparing action of the cystine.

Owing to the extremely variable severity of infective hepatitis and of 'post-arsphenamine' jaundice, the value of any treatment or treatments can only be appraised statistically and after many hundreds of cases have passed through our wards. So far, pre- 